\title{
Superbrittleness of rocks at high confining pressure
}

\author{
B.G. Tarasov The University of Western Australia, Australia
}

\begin{abstract}
The paper discusses the variation of rock brittleness with confining pressure $\sigma_{3}$ for rocks of different hardness, failed under triaxial compression with $\sigma_{1}>\sigma_{2}=\sigma_{3}$. Experimental results presented in the paper show that hard rocks unlike relatively soft rocks increase their brittleness with rising confining pressure $\sigma_{3}$. The harder the rock the greater is the effect of embrittlement. Most hard rocks become hundreds of times more brittle compared with uniaxial compression approaching absolute brittleness. The shear rupture energy at these conditions becomes vanishingly small. Estimations made for Westerly granite show that the maximum brittleness corresponds to $\sigma_{3} \approx 300 \mathrm{MPa}$.

A special shear rupture mechanism is proposed to explain this phenomenon. In accordance with this mechanism the embrittlement results from reduction of friction within the rupture zone with rising confining pressure. The efficiency of this mechanism is a function of rock hardness and confining pressure. In most hard rocks failed within a certain range of confining pressure this mechanism can create transient negative shear resistance - referred to as 'negative friction' - which makes rocks superbrittle and failure abnormally violent. Estimations show that superbrittle rock behaviour takes place at confining pressures corresponding to the seismogenic zone of the earth crust. The new concept advances our knowledge about hard rock properties at great depths and our understanding of mechanisms governing the nucleation of deep seated dynamic events (earthquakes and shear rupture rockbursts).
\end{abstract}

\section{Introduction}

The paper discusses rock brittleness variation under the effect of confining pressure $\sigma_{3}$ for rocks of different hardness tested to failure under triaxial compression $\sigma_{1}>\sigma_{2}=\sigma_{3}$. The analysis concerns rocks that exhibit failure in a form of shear rupture under confined conditions. A decrease in rock brittleness with rising confining pressure $\sigma_{3}$ has been widely reported and is perhaps the most comprehensively studied aspect of rock behaviour. This behaviour is typical for relatively soft rocks and is in agreement with common frictional shear rupture models (Peng and Johnson, 1972; Cox and Scholz, 1988; King and Sammis, 1992; Reches and Lockner, 1994; Mandel, 2000).

The paper draws attention to a less studied hard rock property — increasing brittleness with increase in $\sigma_{3}$ (Stavrogin and Tarasov, 2001; Tarasov and Dyskin, 2005). The paucity of data on post-peak properties of hard rocks results from the impossibility of rupture control within a certain (embrittlement) range of confining pressure $\sigma_{3}$. Analysis of available experimental data conducted in the paper shows that the brittleness variation for hard rocks follows a typical pattern of initially increasing as $\sigma_{3}$ increases, reaching a maximum at some level of $\sigma_{3}$ and then ultimately decreasing since all rocks become ductile at very high $\sigma_{3}$. The harder the rock the greater is the effect of embrittlement. Some rocks show tremendous embrittlement approaching absolute brittleness (see Figure 1 for the definition of 'absolute brittleness').

In general, increasing brittleness of rock with increasing $\sigma_{3}$ is a well known effect. Mechanisms of embrittlement associated with rock material compaction or pore collapse at high confining pressure have been explored by others (Zhang et al., 1990; Wong et al., 1992; Shimada, 2000). Another form of embrittlement was observed in studies of stick-slip phenomenon on existing faults, associated with the transition from stable sliding to stick-slip behaviour (Byerlee and Brace, 1969). However, the mechanism responsible for the brittleness variation of intact hard rocks of low porosity and fine-grained structure has not been explored and is of a very different nature.

In this paper we propose further development of a new shear rupture mechanism (Tarasov and Randolph, 2007, 2008; Tarasov, 2008a, 2008b) that is believed to operate in hard rocks within the embrittlement pressure range. In accordance with this mechanism the embrittlement results from reduction of friction 
within the rupture zone with rising confining pressure. The efficiency of this mechanism is a function of rock hardness and confining pressure. In most hard rocks failed within a certain range of confining pressure this mechanism can create transient negative shear resistance, or 'negative friction', which makes rocks superbrittle and failure abnormally violent. Estimations show that superbrittle rock behaviour takes place at depths corresponding to the seismogenic zone of the earth crust with a maximum brittleness at about $5-10 \mathrm{~km}$.

\section{Rock brittleness variation with confining pressure}

To quantify rock brittleness under conditions of triaxial compression $\sigma_{1}>\sigma_{2}=\sigma_{3}$ we introduce a brittleness index $\mathrm{k}$, which characterises the capability of the rock to self-sustaining failure due to elastic energy accumulated in the material body during loading, and available for rupture development in the post-peak region.

$$
k=\frac{d W_{r}}{d W_{e}}=\frac{E-M}{M}
$$

Where:

$d W_{r}=\frac{d \sigma^{2}(E-M)}{2 E M}$ is the rupture energy.

$d W_{e}=\frac{d \sigma^{2}}{2 E}$ is the accumulated elastic energy available for the rupture process.

$E=\frac{d \sigma}{d \varepsilon}$ is the unloading elastic modulus.

$M=\frac{d \sigma}{d \varepsilon}$ is the post-peak modulus.

All these parameters can be determined from complete experimental stress-strain curves.

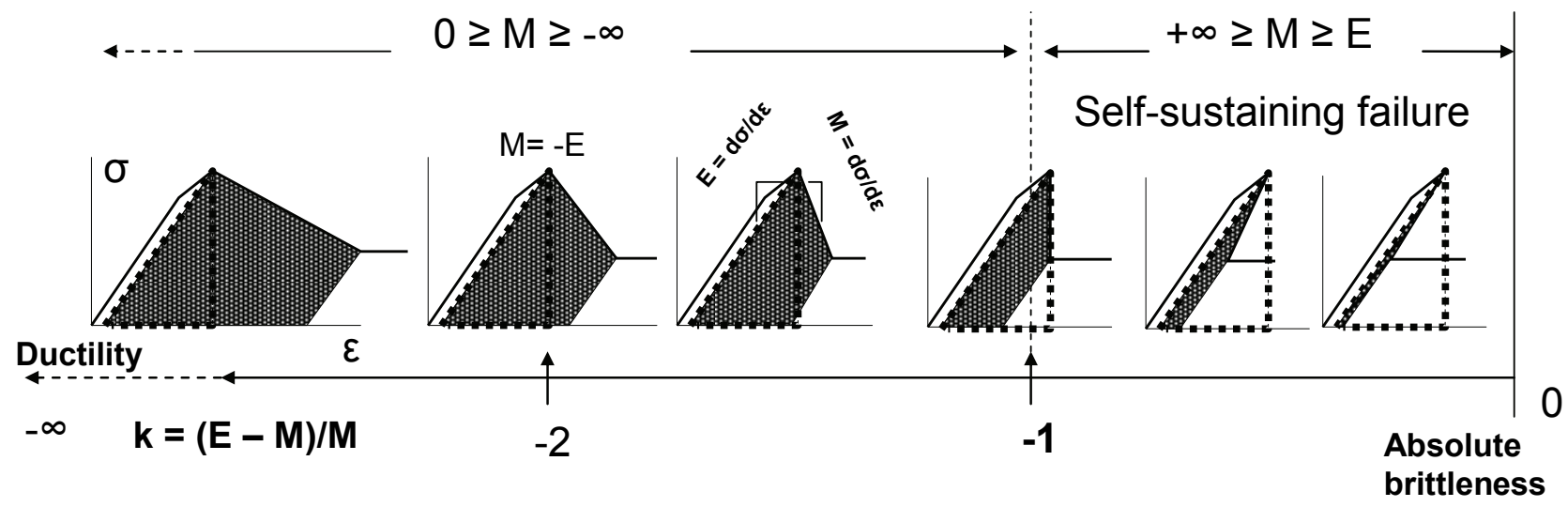

Figure 1 Scale of brittleness index $k=(E-M) / M$ with characteristic shapes of complete stressstrain curves

Figure 1 shows the scale of rock brittleness index $\mathrm{k}$ with brittleness increasing from left to right. Complete curves (differential stress $\sigma=\left(\sigma_{1}-\sigma_{3}\right)$ vs. axial strain $\varepsilon$ ) here illustrate variation in shape of these curves with variation in brittleness. It is supposed for simplicity that pre-peak parts of the curves are the same. Areas restricted by dotted triangles correspond to elastic energy $\mathrm{W}_{\mathrm{e}}$ stored within the rock material at the peak stress. Post-peak parts of the curves characterised by post-peak modulus $\mathrm{M}$ are different for different curves. Shaded areas represent the rupture energy $\mathrm{W}_{\mathrm{r}}$ associated with strength degradation at failure from the peak 
stress to the residual strength (horizontal part of the post-peak curves). The index $\mathrm{k}$ is negative because the elastic energy is treated as positive, while the rupture energy is negative, and its range is $-\infty<\mathrm{k}<0$.

Within the range of brittleness index $-1<\mathrm{k}<0$ the elastic energy $\mathrm{dW}_{\mathrm{e}}$ available from the material exceeds the rupture energy $\mathrm{dW}_{\mathrm{r}}$ providing the self-sustaining failure. The self-sustaining failure has normally a spontaneous character even for a hypothetically perfectly stiff testing machine. The greater is difference between $\mathrm{dW}_{\mathrm{r}}$ and $\mathrm{dW}_{\mathrm{e}}$ the more violent the self-sustaining failure is. At conditions of absolute brittleness $\mathrm{dW}_{\mathrm{r}}=0$ and $\mathrm{k}=0$. For $\mathrm{k}<-1$ the rupture development is not self-sustaining because the rupture energy exceeds the elastic energy stored within the material body. Additional work must be done to cause complete failure.

In special experiments the self-sustaining failure can be provided in controllable regime. For that the excess of elastic energy must be extracted from the material body by the reverse axial strain in accordance with the positive post-peak modulus M. The rupture development in this case becomes stable. Figure 2 shows four sets of curves (differential stress $\sigma=\left(\sigma_{1}-\sigma_{3}\right)$ versus axial strain $\varepsilon$ ) for rocks of different hardness, with the hardness increasing from Figure $2 \mathrm{a}$ to Figure $2 \mathrm{~d}$ ( $\mathrm{a}$ - sandstone, $\mathrm{b}$ - quartzite, $\mathrm{c}$ - Westerly granite, $\mathrm{d}-$ dolerite). Porous (5\%) sandstone (Stavrogin and Tarasov, 2001) represents rocks of relatively low hardness, while Westerly granite (Wawersik and Brace, 1971) and dolerite (Tarasov and Randolph, 2008) represent hard rocks. Quartzite here represents rocks with intermediate properties. All rocks were tested within the pressure range of $0 \leq \sigma_{3} \leq 150 \mathrm{MPa}$. Failure of all the rocks under confined conditions was by a form of shear rupture. Controllable rupture development in the post-peak region at all levels of $\sigma_{3}$ was provided for sandstone and quartzite. For Westerly granite (Figure 2(c)) rupture control was provided within the range of confining pressure $0 \leq \sigma_{3} \leq 11,600 \mathrm{psi} \approx 80 \mathrm{MPa}$. Wawersik and Brace (1971) pointed out that Westerly granite is very unstable in the post-peak zone under uniaxial compression but becomes considerably more stable around $500 \mathrm{psi} \approx 3.5 \mathrm{MPa}$ of confining pressure and more unstable again as $\sigma_{3}$ is raised. At $\sigma_{3}=22,000 \mathrm{psi} \approx 152 \mathrm{MPa}$, control was possible only at the start of the post-peak stage after which explosive-like collapse of the specimens occurred. For $\sigma_{3}>22,000 \mathrm{psi}$ (154 MPa) explosive-like uncontrollable rupture occurred at the peak stress level.

a)

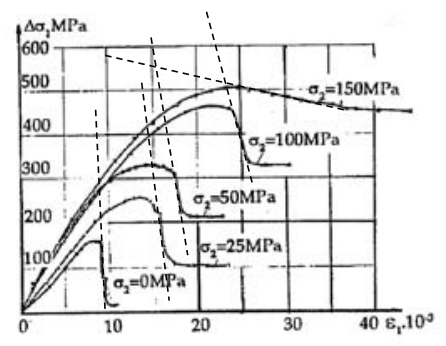

b)

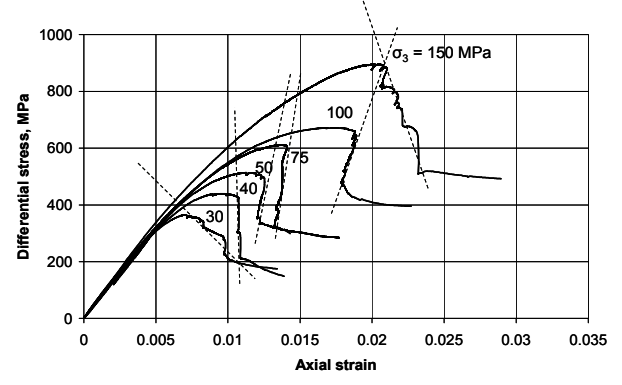

d)

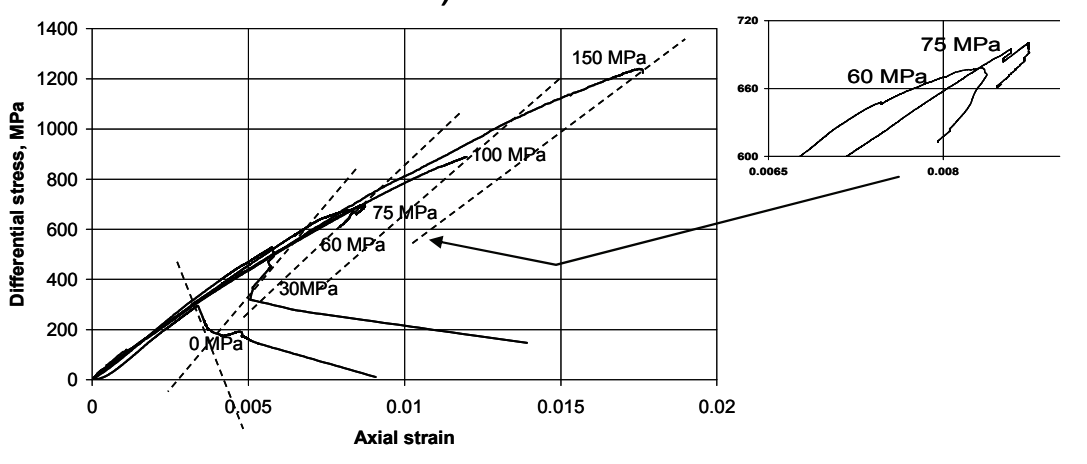

Figure 2 Rocks of different hardness tested at triaxial compression: a) sandstone, b) quartzite, c) Westerly granite, and d) dolerite. e) Controlled stage of the post-peak failure of dolerite specimens at $\alpha_{3}=60$ and $75 \mathrm{MPa}$ 
Failure of dolerite specimens (Figure 2d) was controllable for unconfined conditions and at $\sigma_{3}=30 \mathrm{MPa}$. At greater confining pressures, $\sigma_{3}=60$ and $75 \mathrm{MPa}$, control was possible only at the start of the post-peak stage after which spontaneous (explosive-like) failure took place. The controlled stages of post-peak failure of dolerite specimens at 60 and $75 \mathrm{MPa}$ are shown in Figure $2 \mathrm{e}$ on a larger scale. At $\sigma_{3}=100$ and $150 \mathrm{MPa}$ explosive-like failure occurred just after the peak stress. In all cases uncontrollable failure was accompanied by the release of a huge amount of elastic energy, which caused significant tremors through the very stiff and massive loading system (Tarasov and Dyskin, 2005).

It is important to note that the vast majority of experimental data available today on hard rocks tested under confined conditions involve only the pre-peak deformation stage, due to impossibility of rupture control in the post-peak zone. Post-peak control was provided only at relatively low confining pressures (e.g. Figures 2c, 2d and Lockner et al., 1991; Lockner, 1993) and extremely high confining pressures where rocks become more ductile (Peterson, 1978). The impossibility of rupture control within the intermediate pressure range is explained commonly by technical problems without comprehensive analysis of rock brittleness variation under the effect of confining pressures. Analysis conducted below shows that the main reason for uncontrollable failure is the extraordinary rock embrittlement for these conditions.

Figure $3 \mathrm{a}$ shows the stress-strain curve from Figure $2 \mathrm{e}$ obtained for a dolerite specimen at $\sigma_{3}=60 \mathrm{MPa}$. This curve involves a post-peak part with positive modulus $\mathrm{M}$ where rupture control was provided easily. However, below point A control became impossible. To analyse the reason for that we divided the post-peak curve into four stages with equal intervals of differential stress (Figure 3b). Each stage is characterised by average values of unloading elastic modulus $\mathrm{E}$ and post-peak modulus $\mathrm{M}$. It is assumed that modulus $\mathrm{E}=84,000 \mathrm{MPa}$ is constant for all four stages due to relatively small stress degradation between the peak stress and point $\mathrm{A}$. Figure $3 \mathrm{~b}$ represents a graphical illustration of the relation between modulus $\mathrm{E}$ and $\mathrm{M}$ at failure. At the rupture development from stage (1) to stage (4) modulus $M$ decreases, approaching modulus E. At point $A M=84,500 \mathrm{MPa}$. Areas located between $\mathrm{E}$ and $\mathrm{M}$ lines represent the rupture energy $\mathrm{dW} \mathrm{r}_{\mathrm{r}}=\mathrm{d} \sigma^{2}$ $(\mathrm{E}-\mathrm{M}) / 2 \mathrm{EM}$ which decreases dramatically with the rupture development. Theoretically at $\mathrm{M}=\mathrm{E}$ the rupture energy becomes equal to zero and material exhibits absolute brittleness.

a)

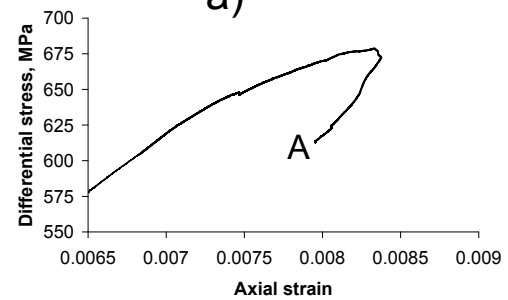

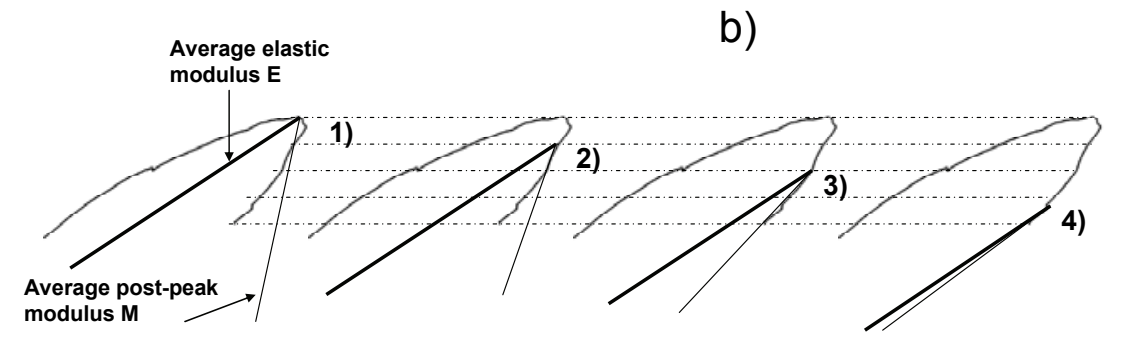

Figure 3 a) Fragment of stress-strain curve for dolerite specimen tested at $\sigma_{3}=60 \mathrm{MPa}$; b) Variation in post-peak modulus $M$ with rupture development

Figure 4a shows the variation of modulus $\mathrm{E}$ and $\mathrm{M}$ versus differential stress for the same specimen, while Figure $4 \mathrm{~b}$ shows variation of the brittleness index $k=(E-M) / M$. At stages (1) and (4) values of the brittleness index are -0.85 and -0.006 correspondingly. On the basis of our analysis we can conclude that the rupture development in this confined condition was accompanied by reduction of the rupture energy, increasing material brittleness. When the value of modulus $\mathrm{M}$ had approached the value of modulus $\mathrm{E}$ (after stage (4)), rupture control became technically impossible. At $\sigma_{3}=75 \mathrm{MPa}$ the reduction of $\mathrm{M}$ with the rupture development occurred more intensively, which shortened the post-peak stage. At greater $\sigma_{3}(100$ and $150 \mathrm{MPa}$ ) values of $\mathrm{M}$ and $\mathrm{E}$ became very close to each other at the onset of the post-peak stage causing uncontrollable failure just after the peak stress. 

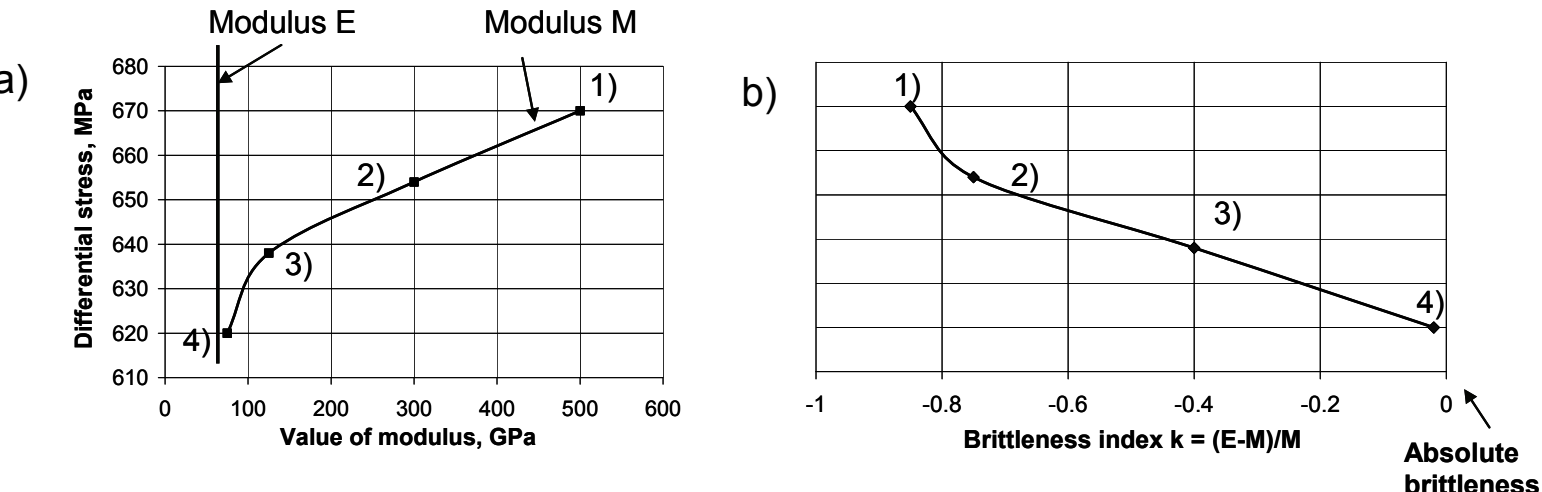

\section{Figure 4 Variation of post-peak modulus $M$ (Figure a) and brittleness index k (Figure b) versus differential stress $\sigma$ for the dolerite specimen tested at $\sigma_{3}=60 \mathrm{MPa}$}

To analyse the brittleness variation with rising confining pressure for the rocks presented in Figure 2 the post-peak curves of all four rocks were approximated by straight lines for calculating the post-peak modulus $\mathrm{M}=\mathrm{d} \sigma / \mathrm{d} \varepsilon$. The lines representing the post-peak slopes for Westerly granite at $\sigma_{3}=22,000 \mathrm{psi}(154 \mathrm{MPa})$ and dolerite at $\sigma_{3}=60$ and $75 \mathrm{MPa}$ are plotted on the basis of small positive slopes of the stress-strain curves obtained experimentally. Taking into account the fact that increasing $\sigma_{3}$ leads to a decrease in the positive post-peak modulus $\mathrm{M}$ the straight lines for dolerite at $\sigma_{3}=100$ and $150 \mathrm{MPa}$ have been postulated to reflect this tendency. The elastic modulus E relevant for Equation (1) is the unloading elastic modulus, which is variable in the post-peak stage of rupture development. For simplicity we use a constant value of E representing an average modulus at the pre-peak stage of deformation. This approximation, however, does not affect the general trend of the brittleness variation with confining pressure.

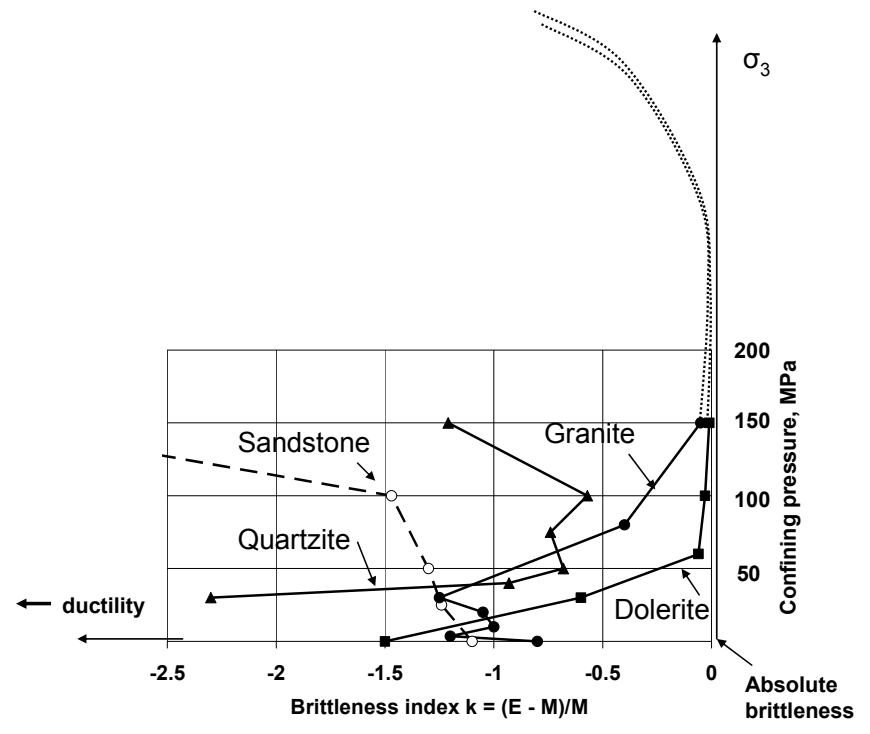

Figure 5 Variation of brittleness index $k=(E-M) / M$ versus confining pressure $\sigma_{3}$ for rocks of
different hardness

Figure 5 shows the variation of brittleness index $\mathrm{k}$ with confining pressure $\sigma_{3}$ for the rocks discussed, with brittleness increasing from left to right. The graph for sandstone shows that increase in $\sigma_{3}$ makes the rock less brittle. This behaviour is typical for soft and insufficiently hard rocks. For the quartzite, increase in $\sigma_{3}$ within the range of 0-100 MPa makes it more brittle. At greater $\sigma_{3}$ the brittleness decreases. The graph for granite shows that, at very low $\sigma_{3}$, the rock brittleness can decrease with rising $\sigma_{3}$ exhibiting features of soft rocks; however, with further increase of $\sigma_{3}$ the granite becomes more and more brittle. Results obtained for the dolerite specimens demonstrate increase in brittleness with rising $\sigma_{3}$. At $\sigma_{3}=75 \mathrm{MPa}$ the dolerite became 250 times more brittle compared with uniaxial compression $\left(\mathrm{k}_{0}=-1.5 ; \mathrm{k}_{75}=0.006\right)$. At $\sigma_{3}=100$ and 
$150 \mathrm{MPa}$ the brittleness increased significantly further. The dashed lines indicate the expected brittleness variation for granite and dolerite at greater $\sigma_{3}$ : the brittleness continues to increase until it reaches a maximum at some level of $\sigma_{3}$ and then decreases since all rocks become ductile at very high $\sigma_{3}$. For less hard rock (such as the quartzite) the mode of brittleness variation is similar but the maximum brittleness is lower and the range of confining pressure where embrittlement takes place is smaller. The softer the rock, the less embrittlement occurs.

\section{Shear rupture mechanisms responsible for rock embrittlement}

\subsection{Frictionless model of primary ruptures}

It is known that the confining pressure $\sigma_{3}$ influences the fracture patterns (Kirby and McCormick, 1984; Shimada, 2000) and three types of fracture patterns are normally distinguished as illustrated in Figure 6.

1. Splitting by long tensile cracks. Experiments show that under uniaxial compression artificial inclined planes inserted in brittle materials cannot propagate in their own plane. They extend in a form of long tensile cracks (wings) oriented in the direction of the major stress $\sigma_{1}$ (Germanovich et al., 1994). Brittle rocks tested under uniaxial conditions and at low confining stresses also fail in this mode (Wawersik and Fairhurst, 1970). In both cases the tensile cracks are caused by tensile stress concentration acting at the edges of artificial or natural micro planes (defects) in the material structure (Horii and Nemat-Nasser, 1985).

2. Distributed micro-cracking. Increasing the confining pressure suppresses the development of long tensile cracks, reducing their length and leading to the formation of local 'shear-crack' defects comprising shear and crack elements. The number of these local defects increases during loading until finally they combine to form a general rupture normally with very rough surfaces (Brace and Bombolakis, 1963; Horii and Nemat-Nasser, 1985; Ashby and Hallam, 1986; Stavrogin and Tarasov, 2001).

(1)

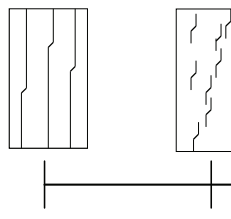

0
(2)
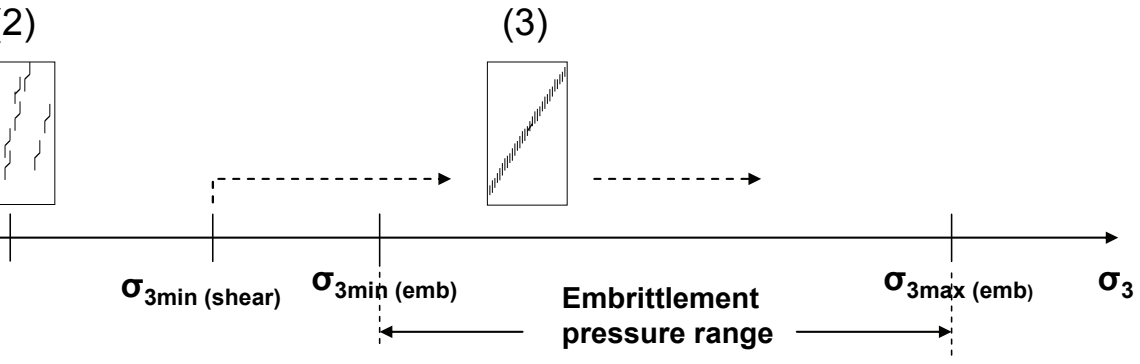

Figure 6 Typical variations in fracture pattern with confining pressure $\sigma_{3}$

3. Shear rupture. Starting from a certain level of $\sigma_{3}=\sigma_{3 \min (\text { shear) }}$ (different for different rocks) the character of failure changes: rocks fail due to formation of a plane macroscopic shear rupture capable of propagating in its own plane. Studies (Reches and Lockner, 1994; Renshaw and Shulson, 2001) show that the macroscopic shear rupture can start from a microscopic shear plane (defect) and propagate due to creation of an echelon of short tensile cracks in front of the propagating rupture.

Despite the fact that in all three cases both shear and crack elements are involved in the failure process the rupture mechanism activated for $\sigma_{3} \geq \sigma_{3 \min (\text { (shear })}$ differs fundamentally from those at lower $\sigma_{3}$. For $\sigma_{3}<\sigma_{3 \min (\text { (shear) }}$ the formation of relatively long tensile cracks changes the stress field in the surrounding area, prohibiting the formation of new neighbour tensile cracks generated on the basis of the existing 'shear-crack' defects. These represent self-isolating features. For $\sigma_{3} \geq \sigma_{3 \min (\text { shear }}$ the tensile cracks become short enough to contribute to the shear rupture but without significantly affecting the stress conditions at the shear rupture tips necessary for the creation of further tensile cracks. The creation of short tensile cracks in front of the rupture tip is the fundamental mechanism providing the shear rupture propagation in its own plane. This mechanism creates the universal structure of shear ruptures represented by an echelon of blocks (or slabs) separated by tensile cracks (Peng and Johnson, 1972; Cox and Scholz, 1988; King and Sammis, 1992; Reches and Lockner, 1994; Mandel, 2000). Such structure is referred to in the literature as a 'domino' or 
'book shelf' structure. Initial angle $\alpha$ of the tensile crack and block inclination to the shear rupture plane is about $30^{\circ}$ (Horii and Nemat-Nasser, 1985). Shear displacement along such structure is accompanied by rotation of the blocks between the rupture surfaces.

Shear rupture is a universal form of rock failure under confined compression, both in the laboratory and in nature. Since the fault structure with an echelon of blocks separated by tensile cracks represents a fundamental feature of shear ruptures, it must play a very important role in rock embrittlement. To understand the reasons of hard rock embrittlement due to confining pressure it is necessary to understand the features of shear rupture formation in hard rocks compared with soft rocks. Figure 7a illustrates the essence of shear rupture mechanism for relatively soft rocks (common concept). All existing shear rupture models consider shear displacement of the rupture faces in the rupture head as frictional process. They suppose that the blocks at rotation are subjected to collapse creating friction within the rupture head. The shear resistance variation along the rupture head for this case is shown in Figure $7 \mathrm{a}$. The cohesive strength $\tau_{\text {coh }}$ and the initial resistance caused by the front blocks are substituted gradually by frictional resistance due to block collapse. At the end of the rupture head the resistance becomes purely frictional $\tau_{\mathrm{f}}$. Within the core zone located behind the fan head the shear resistance is also purely frictional. In accordance with such models the increase in $\sigma_{3}$ increases the friction within the rupture zone including the rupture head which is followed by an increase in rupture energy and decrease in rock brittleness.
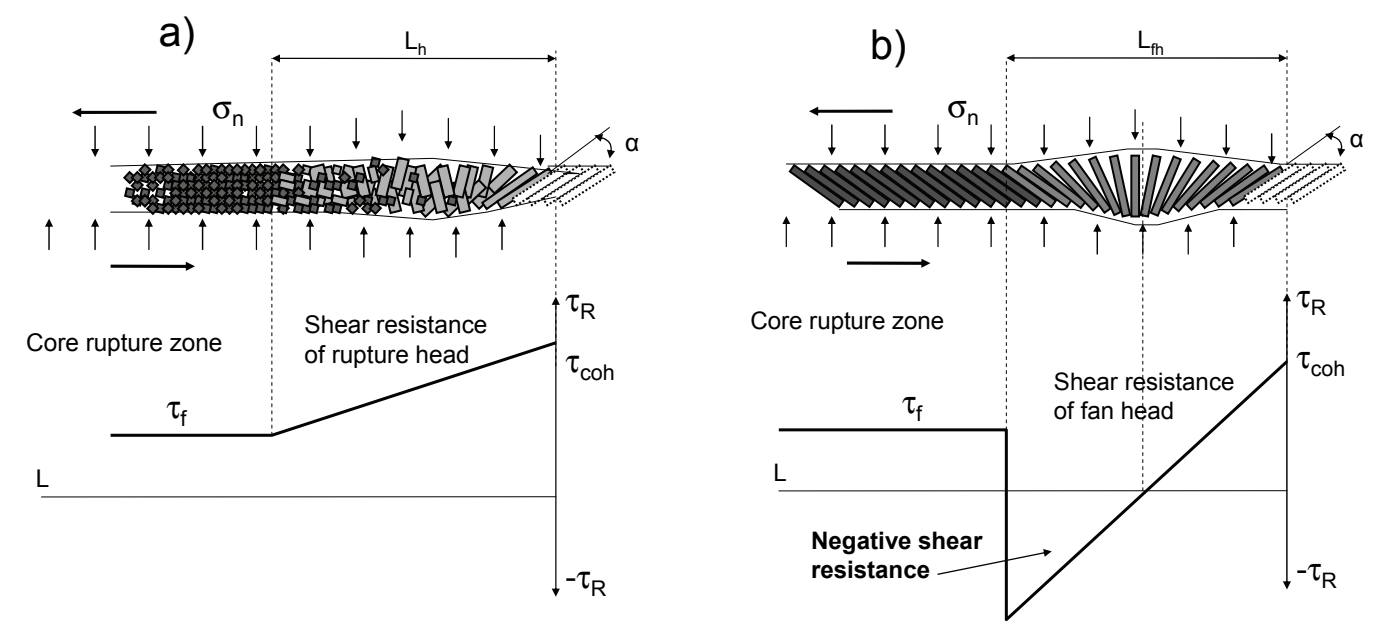

Figure 7 Shear rupture mechanisms; a) common frictional and b) new frictionless models

The new concept (Tarasov, 2008a) proposes that the blocks formed in front of the rupture head can rotate without collapse at shear displacement of the rupture faces (Figure $7 \mathrm{~b}$ ). The rotating blocks in this case operate as hinges eliminating friction. It should be accentuated that blocks of the domino-structure can operate as hinges in hard rocks only because very strong material is required to achieve this. The very high strength of the rotating blocks is provided also by the scale effect: the smaller the block length the stronger it is. Rising confining pressure decreases the tensile crack length which makes the blocks shorter and stronger. That is why the effect of rock embrittlement takes place in hard rocks at high confining pressures only.

The blocks due to consecutive rotation form finally a fan structure within the rupture head. A remarkable feature of the rotating blocks in the second half of the fan structure is the creation of active forces (negative shear resistance) under the effect of the normal stress $\sigma_{\mathrm{n}}$. The graph in Figure $7 \mathrm{~b}$ illustrates the variation of shear resistance along the fan-head rupture. The second part of the graph represents the active forces (negative resistance) assisting the rupture propagation. Due to the fact that all existing fault models consider the fault resistance as frictional we refer to the negative resistance symbolically as 'negative friction'. In the core zone represented by blocks completed their rotation the normal friction is restored.

A physical model in Figure 8 illustrates features of the fan head formation. All blocks of the model are confined by two elastic belts (on top and bottom) representing material of the rupture faces. Normal stress $\sigma_{\mathrm{n}}$ is applied to the structure. This model introduces key roles of elasticity of the face material and normal stress in the fault structure development. Due to elasticity of the face material the rotating blocks are separated by splitting and rotated sequentially, forming a fan-shaped structure. The picture illustrates different stages of 
the rupture propagation. The forces shown indicate schematically the variation in total shear resistance of the growing rupture head (here, $\mathrm{F}$ is the applied force; $\mathrm{F}_{\mathrm{R}}^{\prime}$ and $\mathrm{F}_{\mathrm{A}}^{\prime}$ are reactive and active forces). The forces $\mathrm{F}_{\mathrm{R}}^{\prime}$ and $\mathrm{F}_{\mathrm{A}}^{\prime}$ are functions of normal stress $\sigma_{\mathrm{n}}$, modulus $\mathrm{E}$ of the face material and geometrical characteristics of the rotating blocks (e.g. length $r$, initial angle $\beta_{\mathrm{o}}$ ). During formation of the first half of the fan head the shear resistance increases and reaches maximum, $F_{R \max }^{\prime}$, at the moment when the first half of the fan structure is formed. This rupture process takes place during the pre-peak stage of the material loading.

Due to the creation of an active force $\mathrm{F}_{\mathrm{A}}^{\prime}$ (under the effect of normal stress $\sigma_{\mathrm{n}}$ ), at formation of the second half of the head the total shear resistance of the fan head decreases. At completion of the fan-structure formation the value of the active force becomes equal to the reactive force $\mathrm{F}_{\text {Amax }}^{\prime}=\mathrm{F}_{\mathrm{Rmax}}^{\prime}$. Thus the fanstructure represents a self-equilibrating mechanism and can move as a wave without shear resistance. Elastic energy accumulated within the face material in the first half of the fan head releases in the second half. In the idealised model the resistance to rupture propagation is determined only by the tensile strength of the material associated with consecutive formation (splitting) of blocks in front of the propagating rupture. This resistance can be extremely small due to low tensile strength and very small length of rotating blocks (less than $1 / 10 \mathrm{~mm}$, see Tarasov and Randolph, 2008). It is important that the fan head can propagate independently of the core zone, which can remain immobile due to high frictional resistance. In this situation the rupture energy is determined by shear resistance of the fan head only.

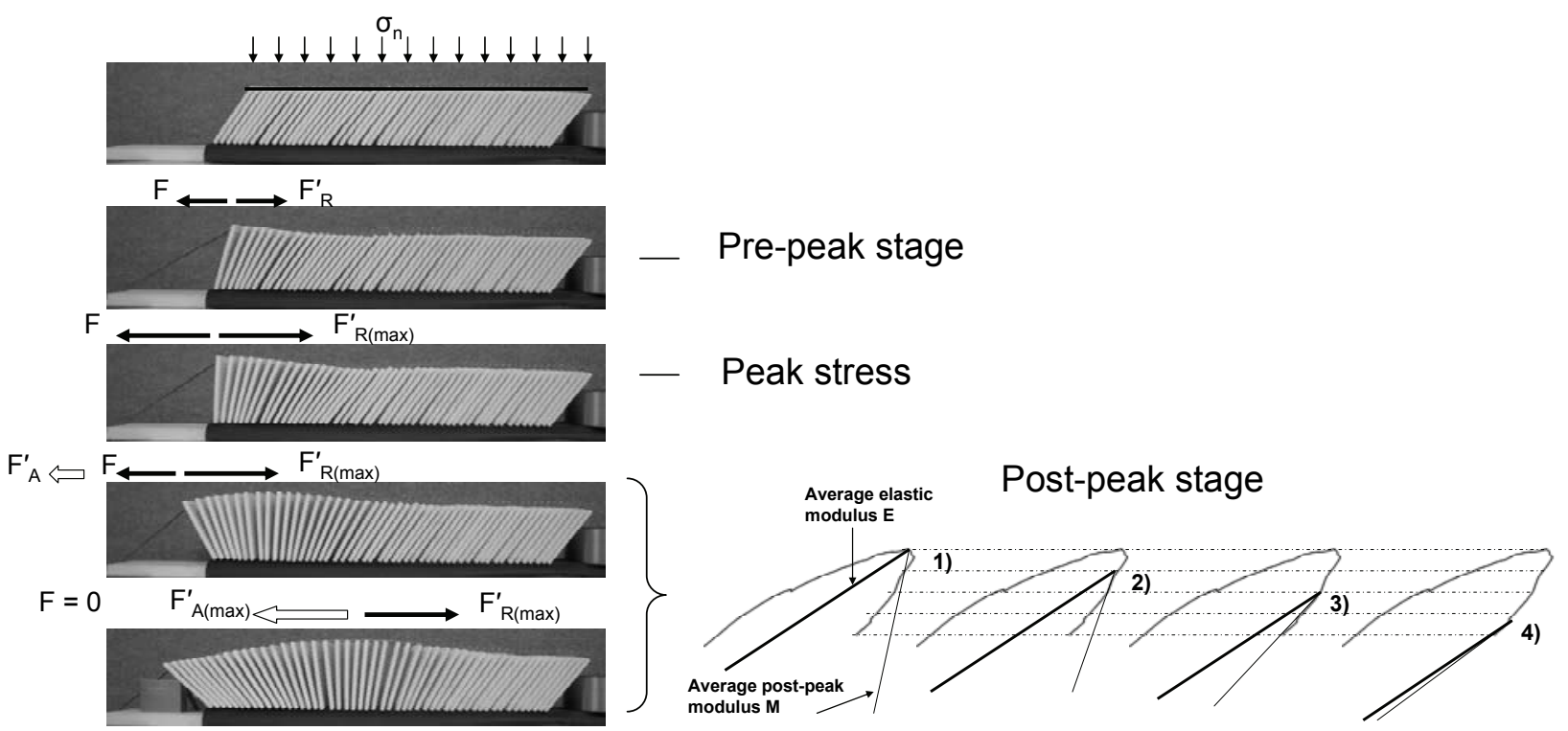

Figure 8 Physical model of the fan head formation

The previously discussed (Figure 3b) decrease in rupture energy with deformation in the post-peak region is caused by the development of the second half of the rupture head (see Figure 8). The rupture energy decreases and becomes extremely small when the fan head is completed. After that the rupture control becomes impossible because the fan head starts propagating dynamically independently on the rupture core. Experiments conducted on the physical fan-head model (Figure 8) showed that the length $\mathrm{L}_{\mathrm{fh}}$ of the fan head is a function of the normal stress $\sigma_{\mathrm{n}}$, the elastic modulus $\mathrm{E}$ of the rupture face material and geometrical characteristics of the domino-structure. It is important that the increase in $\sigma_{\mathrm{n}}$ reduces the fan head length $\mathrm{L}_{\mathrm{fh}}$. This explains why with increase in $\sigma_{3}$ the controllable stage of the post-peak deformation decreases. Hence, we can conclude that unlike frictional rupture mechanisms where $\sigma_{3}$ contracts the rupture development in the frictionless rupture mechanism $\sigma_{3}$ assists the rupture propagation.

\subsection{Frictionless model of complex shear ruptures}

Generally faults represent complex formations involving relatively wide rupture zones of crushed rock which implies very high rupture energy and, consequently, relatively low brittleness. However, a specific rupture mechanism governing the fault development provides frictionless rupture conditions within the fault zone at 
different stages of the fault development which makes the failure process very brittle. This mechanism is discussed below.

It is known that segmentation is a fundamental feature of fault development (Scholz, 2002; De Joussineau and Aydin, 2009). Segmented structure of fault zones extends throughout the seismogenic depth, deeper that $10 \mathrm{~km}$ in the earth's crust (Li et al., 1994; Nishigami, 2000). Faults are composed of essential structural elements: fault segments with an en echelon array and fault jogs (steps). These elements are nested to form a hierarchical geometry as a whole. Different hypotheses have been proposed to explain the reasons for fault segmentation (Segall and Pollard, 1980; Sibson, 1985; Aydin and Shultz, 1990; Scholz, 2002; De Joussineau and Aydin, 2009) but there is still no consensus regarding the segmentation mechanism. A recent laboratory study of fault evolution conducted by Otsuki and Dilov (2005) on a relatively soft rock (calcareous siltstone), where it was possible to observe the rupture process, showed a number of very important features. One of them is the fact that segmentation is a result of advanced triggering of a new rupture (new segment) in front of the propagating current rupture (current segment). Such advanced triggering of new segments in hard rocks at great depth was earlier reported for earthquake faults, based on analysis of seismological data (Wyss and Brune, 1967). The triggering is caused by the stress transfer ahead of the current segment through rock mass already stressed close to failure. The current and new segments propagating toward each other form a jog (step) where they meet.

Mechanisms of segmentation and jog formation in hard rocks at high confining pressure have some features compared with soft rocks. Figure 9a shows a current segment propagating from left to right (bold arrow). Hollow arrows show directions of the applied shear stress. Zones of tensile and compressive stresses as typically generated in areas adjoining the heads of any shear rupture are indicated as T and C. Potential new segments triggered in front of the current one are shown by short arrows. The current and new segments can form compressional or extensional jogs where they meet, depending on which side of the current segment (tensional or compressional) the new segment was generated. In general the formation of both types of jogs (compressional and extensional) is possible (Segall and Pollard, 1980; Du and Aydin, 1995). However, analysis of faults formed at great depths in deep mines (Ortlepp, 1997) suggests that compressional jogs predominate under such conditions. We can suppose that the reason for that is rock embrittlement caused by the additional compression. It should be emphasised that the whole rock mass surrounding the propagating segment is at ultimately stressed conditions and on the verge of failure. A very small increase in stress (due to stress transfer) or increase in rock brittleness can be sufficient for the new rupture generation.

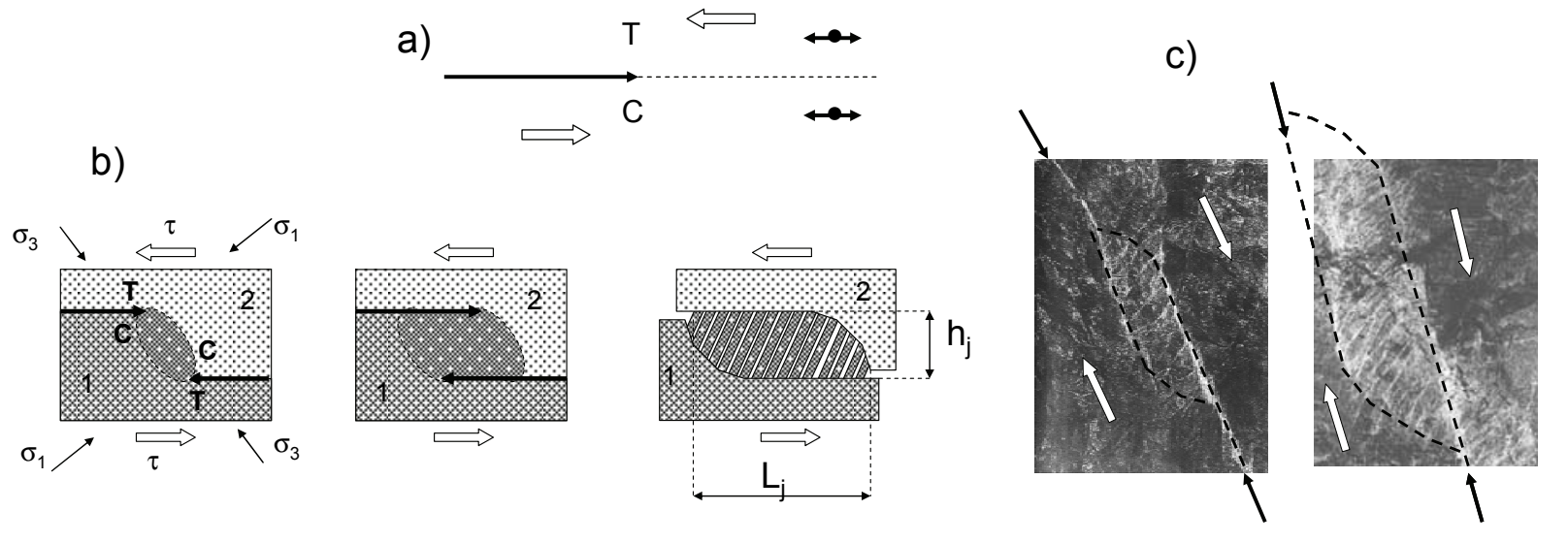

\section{Figure 9 Model of jog formation}

Figure $9 \mathrm{~b}$ shows three phases of linkage between two segments (bold arrows) propagating towards each other (Tarasov and Ortlepp, 2007). Figure 9b (left) indicates the directions of the applied stresses against the propagating segments. The rock mass surrounding the approaching segments is theoretically divided into two massive blocks ( 1 and 2) pressed against each other by the applied stresses. The propagation of the segments decreases shear resistance between the massive blocks along these segments, which overstresses an area located between the tips of the approaching segments (Segall and Pollard, 1980). With further propagation of the rupture segments they confine a zone that is now overstressed (Figure 9b, middle). When the extending overlapped zone in hard brittle rocks reaches some critical length it fractures dynamically into an echelon of 
rotating blocks (slabs) due to shear of the overlapped zone between the parallel faces of the massive blocks 1 and 2 (Figure 9b, right). After that the segments stop propagating. The initial orientation of the tensile cracks separating the rotating blocks is parallel to the major stress $\sigma_{1}$. We refer to this type of shear rupture as joining shear rupture with length $L_{j}$ and width $h_{j}$. Photographs (from Ortlepp, 1997) of natural jogs formed in quartzite of a deep South Africa mine are shown in Figure 9c.

Experiments conducted by Otsuki and Dilov (2005) showed also the following important results. 1) Faults are multi-hierarchical formations. 2) Once a number of segments of a given hierarchical rank coalesce, they behave as a whole as a new and longer segment of one higher rank. 3) Segment of higher rank can trigger a new segment (rupture) at greater distance. 4) The new triggered segment starts as a primary rupture.

Figure 10a shows schematically three stages associated with development of three types of segments of different rank. Shear stress direction here is indicated by open arrows, the fault propagating from left to right. The fault nucleates as a primary rupture because the self-equilibrating fan-head mechanism mobilised in very thin primary ruptures is the most economical shear rupture mechanism. When the primary rupture becomes sufficiently long a new primary rupture can be triggered in front of the current one at a distance $\mathrm{x}_{\mathrm{I}}$ due to stress transfer. Further propagation of these ruptures can trigger the third one and so on. On meeting, these ruptures play a role of segments of rank-I and form corresponding joining ruptures. The joining ruptures in combination represent a new segment of higher rank-II. The rank-II segment can trigger a series of new primary ruptures at different distances with maximum remoteness of $\mathrm{x}_{\mathrm{II}}$. The key feature of fault segmentation is the fact that a new segment triggered by the current segment of any rank nucleates as a primary rupture. At its propagation towards the current segment (and in the opposite direction) the new segment will be subjected to similar evolution as the current segment has been subjected. After linkage of a number of rank-II segments due to creation of corresponding joining ruptures, the next rank-III segment will be formed (shown on a smaller scale $\approx 1: 5$ ). Further development of this fault will be accompanied by creation of higher rank segments. Figure 10b shows natural faults formed in accordance with the discussed mechanism due to combination of a set of joining ruptures.

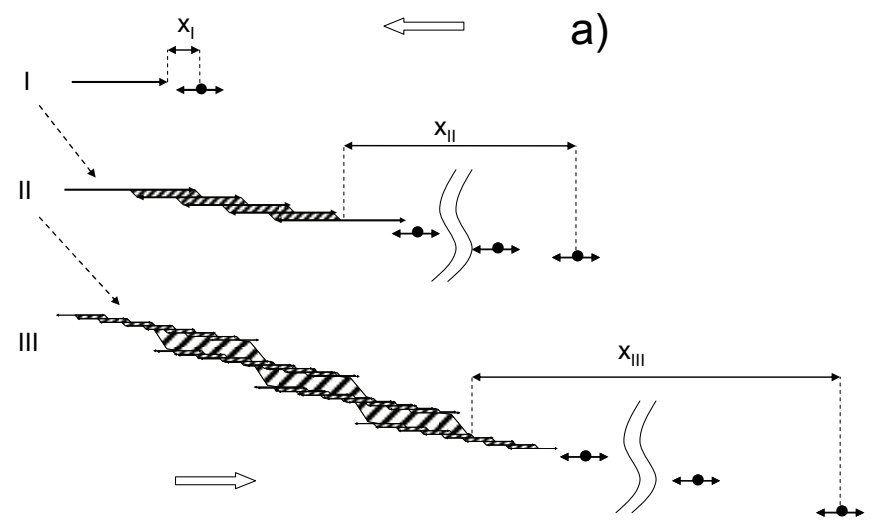

b)
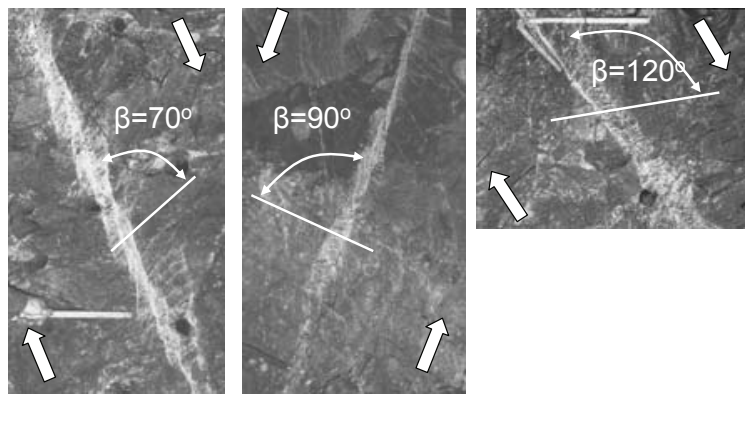

Figure 10 a) evolution of fault structure with development of segments of different rank; b) natural faults formed due to combination of joining ruptures

Important feature is that blocks representing the domino structure of joining ruptures can be subjected to rotation at fault displacement. Figure 10b illustrates this fact. Angle $\beta$ here indicates different stages of the block rotation caused by the fault displacement. An idealised fault model involving an echelon of rotating blocks (Tarasov and Randolph, 2008) is shown in Figure 11a. Shear F and normal N forces are applied to the model. Figure $11 \mathrm{~b}$ illustrates the variation in normalised fault resistance $\mathrm{F} / \mathrm{N}$ as the angle $\beta$ increases during shear displacement of the fault. The resistance decreases, reaching zero at $\beta=90^{\circ}$, beyond which it becomes negative (releasing energy). The negative resistance ('negative friction') is provided by the normal force $\mathrm{N}$ (function of $\sigma_{3}$ ) existing across the fault and which encourages block rotation beyond $\beta=90^{\circ}$, consequently assisting the fault displacement. This mechanism makes the material extremely brittle, because of the loss of any positive resistance over a finite displacement, and the failure process is inevitably spontaneous and abnormally violent. Once the blocks have completed their rotation the fault structure becomes very compact again and the frictional resistance is restored sharply. 
(i)

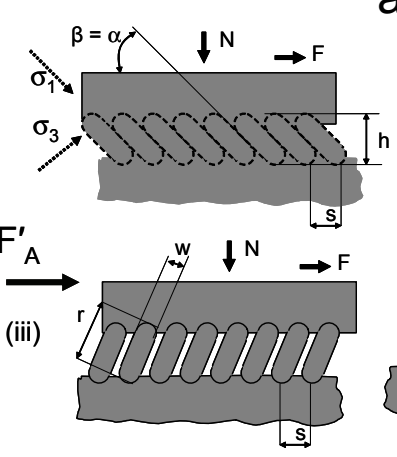

a)

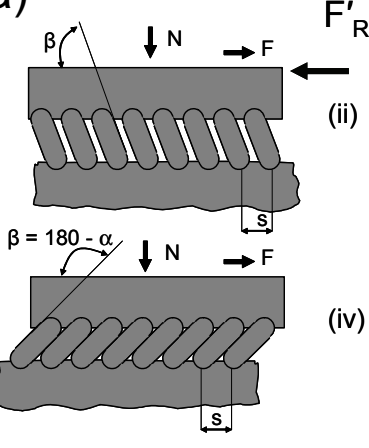

b)

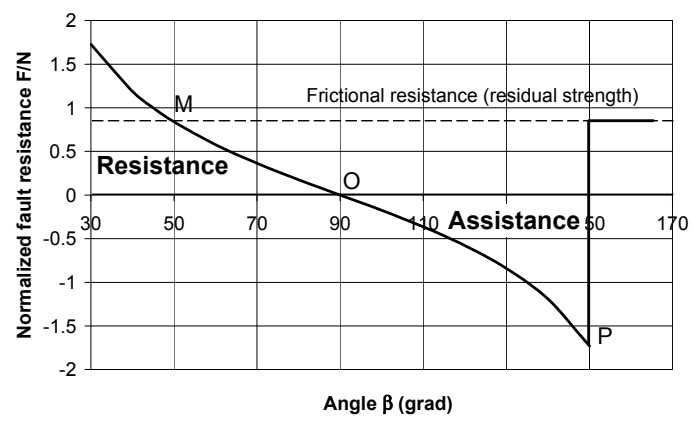

Figure 11 Model of a joining rupture at displacement accompanied by block rotation

The most important feature of the fault structure evolution (Figure 10a) relevant to the main subject of this paper is the fact that low rank segments with corresponding joining ruptures represent basic elements of any higher rank segment for any fault (including very large ones). At fault development, frictionless conditions can be provided first of all in low rank segments where relatively small displacement is required to rotate blocks of joining ruptures up to angle $\beta>90^{\circ}$. When the frictionless conditions have reached the displacement along the low rank segments occurs extremely violently. Relatively thin localized zones of very intensive destruction can be observed in practice in each fault. The initial frictionless structure of these segments is completely destroyed by explosive-like extensive shear. Higher rank segments with domino structure, where blocks rotate with angle $\beta<90^{\circ}$, serve as a damping mechanism accommodating large fault displacement. Hence, we can conclude that low rank segments are actually responsible for high rock brittleness.

\section{$4 \quad$ Mechanism of brittleness variation with confining pressure}

\subsection{Model of brittleness variation}

Now we can discuss the reason for the specific rock brittleness variation with confining pressure shown in Figure 5. Let us consider first the variation in brittleness versus confining pressure $\sigma_{3}$ on the basis of experimental results presented in Figure 5 for Westerly granite and dolerite. Figure 12a illustrates this variation schematically.

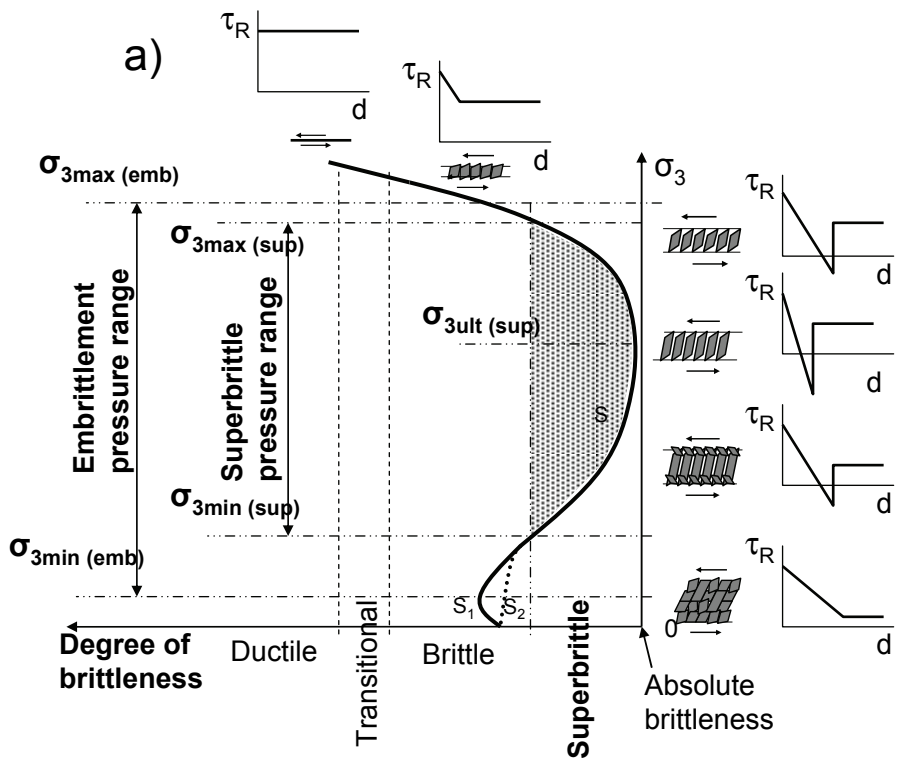

b)

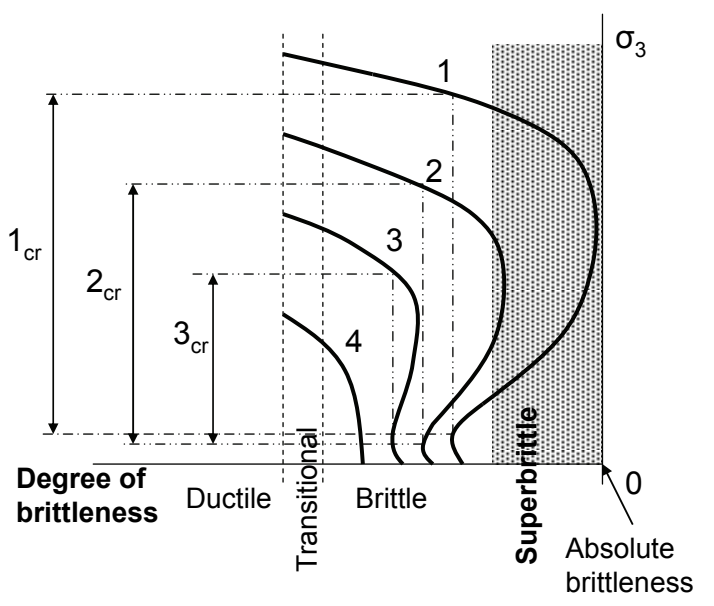

Figure 12 Mechanism responsible for brittleness variation versus confining pressure $\sigma_{3}$ 
The horizontal axis here represents the degree of brittleness and involves three traditional categories (brittle, transitional, ductile) as well as a new one - superbrittle. Figure 12a explains the essence of the rock brittleness variation with $\sigma_{3}$ showing fragments of shear ruptures with characteristic features of the fault structure (rotating blocks). Within the range of confining pressure $0-\sigma_{3 \min (\mathrm{emb})}$ the brittleness variation can accord with the commonly accepted frictional model due to collapsing of the long rotating blocks (curve $\mathrm{S}_{1}$ observed for Westerly granite). Within the embrittlement pressure range, $\sigma_{3 \min (\mathrm{emb})}-\sigma_{3 \max (\mathrm{emb}) \text {, due to }}$ shortening of the rotating blocks, the frictionless mechanism is activated, increasing the rock brittleness compared with the frictional rupture mechanism. The efficiency of the frictionless mechanism is determined by how perfect and uniform the fault structure is. At the low end of the embrittlement pressure range, when the relative length (length/thickness) of the block is still large, the blocks are subjected to partial destruction (buckling) as they rotate. At higher $\sigma_{3}$, with shorter blocks, this imperfection decreases, rendering the frictionless mechanism more efficient. The optimal efficiency takes place at $\sigma_{3 u l t(e m b)}$ when the blocks rotate with minimum destruction making the material ultimately brittle. At greater $\sigma_{3}$ the efficiency reduces because shorter blocks gradually lose any potential for creating negative resistance from rotation. Finally very short blocks lose this capability completely and the rock behaviour returns to the commonly accepted frictional mode. Idealised stress-displacement curves on the right illustrate evolution of the rupture resistance with displacement for different conditions of the rotating blocks, showing the negative shear resistance occurring over a certain $\sigma_{3}$ range.

In accordance with this model of rock embrittlement, two specific zones of confining pressure $\sigma_{3}$ can be distinguished. 1) Embrittlement pressure range $\left(\sigma_{3 \min (\mathrm{emb})}-\sigma_{3 \max (\mathrm{emb})}\right)-$ a zone where the frictionless mechanism is activated decreasing the frictional rupture resistance. 2) Superbrittle pressure range $\left(\sigma_{3 \min (\text { (sup) }}-\sigma_{3 \max (\text { sup })}\right)$ - a zone where the frictionless mechanism is capable of creating 'negative friction'. This zone is shown by the shaded area. Figure 12b shows theoretical curves illustrating brittleness variation for four rocks of different hardness (in accordance with Figure 5). The embrittlement pressure range for rocks 1, 2, and 3 are indicated in the picture. The softer the rock the less embrittlement occurs. Soft rocks (4) with normal frictional rupture mechanism do not exhibit embrittlement at all.

\subsection{Low and high pressure boundaries of the frictionless mechanism operation}

Using experimental data we can estimate stress boundaries for embrittlement $\left(\sigma_{3 \min (\mathrm{emb})}, \sigma_{3 \max (\mathrm{emb})}\right)$ and superbrittle behaviour $\left(\sigma_{3 \min (\text { sup) }}, \sigma_{3 \max (\text { sup })}\right)$ for certain rocks. The lower limit for embrittlement $\sigma_{3 \min (\mathrm{emb})}$ corresponds to the confining pressure from which rock brittleness starts to increase. This may be estimated approximately for Westerly granite, dolerite and quartzite as $30 \mathrm{MPa}$. The lower limit for superbrittle behaviour $\sigma_{3 \min (\text { sup })}$ corresponds approximately to the confining stress at which rupture control becomes impossible (when the effect of 'negative friction' comes into play). Here we estimate roughly that $\sigma_{3 \min (\text { sup })} \approx 100-150 \mathrm{MPa}$ for Westerly granite and $\sigma_{3 \min (\text { (sup) }} \approx 50-60 \mathrm{MPa}$ for dolerite.

What is the upper level, $\sigma_{3 \max (e m b)}$, at which the frictionless mechanism should be suppressed and the rupture mechanism return to the commonly assumed frictional response? We can estimate this on the basis of the following experimental results. An important change in the fracture mechanism was observed experimentally by Shimada (2000) at the level of confining pressure when the cohesive strength equals the frictional strength. Two types of brittle fracture, 'low-pressure' and 'high-pressure' types, were distinguished:

1. The low-pressure type fracture occurs when the cohesive strength is higher than the frictional strength, the main features being: a) numerous microcracks and crushed zones associated with the main fault, which is oriented at $15-40^{\circ}$ to the major stress $\sigma_{1}$ direction; b) rapid increase in acoustic emission (AE) as a final explosive-like fracture is approached.

2. The high-pressure type fracture occurs when the cohesive strength is lower than the frictional strength, with characteristic features being: (a) there are fewer microcracks in total and they are not concentrated close to the main fault but are homogeneously distributed throughout the specimen, suggesting that cataclastic ductile flow could occur; (b) AE activity remains constant followed by a sudden final fracture; (c) the main fault is sharp and oriented at approximately $45^{\circ}$ to the compressive stress $\sigma_{1}$ direction. 


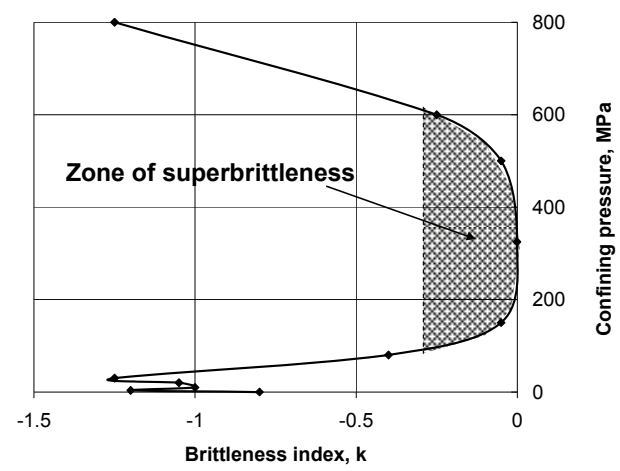

Figure 13 Variation of brittleness index k versus confining pressure $\sigma_{3}$ for Westerly granite

It is known that $\mathrm{AE}$ events in a brittle rock mainly correspond to the generation of microcracks. The frictionless mechanism discussed above is associated with intensive microcracking in the fan head before instability, and in the head and joining ruptures during instability. At high $\sigma_{3}>\sigma_{3 \max (\mathrm{emb})}$ the frictionless mechanism is substituted by a frictional shear rupture mechanism that cannot generate such AE activity. On the basis of the above experiments we can suppose that the frictionless ruptures described here correspond to a form of low-pressure rupture. It is established by Shimada (2000) that at room temperature the confining pressure boundary between low and high-pressure ruptures corresponds to $800 \mathrm{MPa}$ for Mannari granite. This pressure level can be considered as the high pressure boundary $\left(\sigma_{3}=\sigma_{3 \max (\mathrm{emb})}\right)$ for the frictionless mechanism in this rock at room temperature. The high pressure boundary for superbrittle rock behaviour $\left(\sigma_{3}=\sigma_{3 \max (\text { sup })}\right)$ should be lower. Special experimental studies are needed to determine the exact pressure level. Here we estimate roughly the high pressure boundary for superbrittle behaviour for Mannari granite as $\sigma_{3 \max (\text { sup) }} \approx 600 \mathrm{MPa}$. Westerly granite has similar mechanical properties to Mannari granite (Shimada, 2000). Hence, we can suppose that for Westerly granite boundary levels of confining pressure are: $\sigma_{3 \min (\mathrm{emb})} \approx 30 \mathrm{MPa}, \sigma_{3 \max (\mathrm{emb})} \approx 800 \mathrm{MPa}, \sigma_{3 \min (\text { (sup) }} \approx 100-150 \mathrm{MPa}$ and $\sigma_{3 \max (\text { sup })} \approx 600 \mathrm{MPa}$. Figure 13 shows variation of brittleness index $\mathrm{k}$ versus confining pressure for Westerly granite in accordance with the above estimations. The granite should exhibit maximum brittleness at about $\sigma_{3 \text { ult (sup) }} \approx 300 \mathrm{MPa}$.

Applying these results to the earth's crust we can estimate that: $\sigma_{3 \min (\mathrm{emb})} \approx 30 \mathrm{MPa}(\approx 1 \mathrm{~km})$, $\sigma_{3 \max (\mathrm{emb})} \approx 800 \mathrm{MPa}(\approx 27-30 \mathrm{~km}), \sigma_{3 \min (\text { (sup) }} \approx 100-150 \mathrm{MPa}(\approx 3.5-5 \mathrm{~km}), \sigma_{3 \max (\text { (sup) }} \approx 600 \mathrm{MPa}(\approx 17-20 \mathrm{~km})$ and $\sigma_{3 \text { ult (sup) }} \approx 300 \mathrm{MPa}(\approx 10 \mathrm{~km})$. We can expect that the frictionless mechanism is very sensitive to the elevated temperature at great depth that should decrease the high pressure boundaries $\left(\sigma_{3 \max (e m b)}\right.$ and $\left.\sigma_{3 \max (\text { sup) }}\right)$. The obtained estimations allow supposing that elevated rock brittleness and superbrittle behaviour can be the main factor determining the position of the seismogenic zone in the earth's crust and that earthquake depth activity is a function of rock embrittlement with depth: the more brittle the rock behaviour the greater is the earthquake activity. The new concept advances our knowledge about hard rock properties at great depths and our understanding of mechanisms governing the nucleation of deep seated dynamic events (earthquakes and shear rupture rockbursts).

\section{Acknowledgements}

This work was supported over a number of years by the Centre for Offshore Foundation Systems (COFS) at the University of Western Australia. This support is gratefully acknowledged.

\section{References}

Ashby, M.F. and Hallam, S.D. (1986) The failure of brittle solids containing small cracks under compressive stress states, Acta Metallurgica, Vol. 34, pp. 497-510.

Aydin, A. and Schultz, R.A. (1990) Effect of mechanical interaction on the development of strike-slip faults with echelon patterns, Journal of Structural Geology, Vol. 12, No. 1, pp. 123-129.

Brace, W.F. and Bombolakis, E.G. (1963) A note on brittle crack growth in compression, Journal of Geophysical Research, Vol. 68, pp. 3709-3713.

Byerlee, J.D. and Brace, W.F. (1969) High-pressure mechanical instability in rocks, Science, Vol. 164, pp. 713-715. 
Cox, S.J.D. and Scholz, C.H. (1988) On the formation and growth of faults: an experimental study, Journal of Structural Geology, Vol. 10, pp. 413-430.

De Joussineau, G. and Aydin, A. (2009) Segmentation along strike-slip faults revisited, Pure and Applied Geophysics, Vol. 166, pp. 1575-1594.

Du, Y. and Aydin, A. (1995) Shear fracture patterns and connectivity at geometric complexities along strike-slip faults, Journal of Geophysical Research, Vol. 100, pp. 18.093-18.102.

Germanovich, L.N., Salganik, R.L., Dyskin, A.V. and Lee, K.K. (1994) Mechanisms of brittle failure of rock with preexisting cracks in compression, Pure and Applied Geophysics, Vol. 143, pp. 117-149.

Horii, H. and Nemat-Nasser, S. (1985) Compression-induced microcrack growth in brittle solids: Axial splitting and shear failure, Journal of Geophysical Research, Vol. 90, pp. 3105-3125.

King, G.C.P. and Sammis, C.G. (1992) The mechanisms of finite brittle strain, PAGEOPH, Vol. 138, No. 4, pp. 611-640.

Kirby, S.H. and McCormick, J.W. (1984) Inelastic properties of rocks and minerals: strength and rheology, In CRC Handbook of Physical Properties of Rocks, R.S. Carmichael (ed), Boca Raton, Florida: CRC Press, Vol. 3, pp. 139-280.

Li, Y.G., Vidale, J.E., Aki, K., Marone, C.J. and Lee, W.H.K. (1994) Fine structure of the Landers zone: Segmentation and the rupture process, Science, Vol. 256, pp. 367-370.

Lockner, D.A., Byerlee, J.D., Kuksenko, V., Ponomarev, A. and Sidorin, A. (1991) Quasi-static fault growth and shear fracture energy in granite, Nature, Vol. 350, pp. 39-42.

Lockner, D.A. (1993) The role of acoustic emission in the study of rock fracture, International Journal of Rock Mechanics and Mining Science and Geomechanics Abstracts, Vol. 30, No. 7, pp 883-899.

Mandel, G. (2000) Faulting in brittle rocks, Springer-Verlag Berlin Heidelberg.

Nishigami, K. (2000) Deep crustal heterogeneity along and around the San Andreas fault system in central California and its relation to the segmentation, Journal of Geophysical Research, Vol. 105, pp. 7983-7998.

Ortlepp, W.D. (1997) Rock fracture and rockbursts, The South African Institute of Mining and Metallurgy, Johannesburg.

Otsuki, K. and Dilov, T. (2005) Evolution of hierarchical self-similar geometry of experimental fault zones: Implications for seismic nucleation and earthquake size, Journal of Geophysical Research, Vol. 110, B03303, doi: 10.1029/204JB003359.

Peng, S. and Johnson, A.M. (1972) Crack growth and faulting in cylindrical specimens of Chelmsford granite, International Journal of Rock Mechanics and Mining Science, Vol. 9, pp. 37-86.

Peterson, M.S. (1978) Experimental rock deformation - the brittle field, Springer-Verlag, Berlin Heidelberg New York.

Reches, Z. and Lockner, D.A. (1994) Nucleation and growth of faults in brittle rocks, Journal of Geophysical Research, Vol. 99, No. B9, pp. 18159-18173.

Renshaw, C.E. and Shulson, E.M. (2001) Universal behaviour in compressive failure of brittle materials, Nature, Vol. 412, pp. 897-900.

Scholz, C.H. (2002) The mechanics of earthquakes and faulting, Cambridge University Press.

Segall, P. and Pollard, D.D. (1980) Mechanics of discontinuous faults, Journal of Geophysical Research, Vol. 85, pp. 555-568.

Shimada, M. (2000) Mechanical behaviour of rocks under high pressure conditions, Balkema.

Sibson, R.H. (1985) Stopping of earthquake ruptures at dilational fault jogs, Nature 316, pp. 248-251.

Stavrogin, A.N. and Tarasov, B.G. (2001) Experimental physics and rock mechanics, Balkema.

Tarasov, B.G. and Dyskin, A.V. (2005) The phenomenon of anomalous rock embrittlement, in Proceedings Sixth International Symposium on Rockburst and Seismicity in Mines (RaSiM6), Y. Potvin and M. Hudyma (eds), Australian Centre for Geomechanics, Perth, Australia, pp. 311-317.

Tarasov, B.G. and Randolph, M.F. (2008) Frictionless shear at great depth and other paradoxes of hard rocks, International Journal of Rock Mechanics and Mining Science, Vol. 45, pp. 316-328.

Tarasov, B.G. and Randolph, M.F. (2007) Paradoxical features of primary shear fractures and general faults, in Proceedings Fourth International Seminar on Deep and High Stress Mining (Deep Mining07), Y. Potvin (ed), Australian Centre for Geomechanics, Perth, Australia, pp. 165-182.

Tarasov, B.G. and Ortlepp, W.D. (2007) Shock loading-unloading mechanism in rockburst shear fractures in quartzite causing genesis of polyhedral sub-particle in the fault gouge, in Proceedings Fourth International Seminar on Deep and High Stress Mining, Y. Potvin (ed), Australian Centre for Geomechanics, Perth, Australia, pp. 183-192.

Tarasov, B.G. (2008a) Intersonic shear rupture mechanism, International Journal of Rock Mechanics and Mining Science, Vol. 45, pp. 914-928.

Tarasov, B.G. (2008b) New insight into the nature of shear rupture propagation in pristine rocks and pre-existing faults, Keynote address, in Proceedings First Southern Hemisphere International Rock Mechanics Symposium (SHIRMS), Y. Potvin, J. Carter, A. Dyskin and R. Jeffrey (eds), Australian Centre for Geomechanics, Perth, Australia, Vol. 2 - Fundamental and Petroleum, pp. 37-68. 
Wawersik, W.R. and Fairhurst, C. (1970) A study of brittle rock fracture in laboratory compression experiments, International Journal of Rock Mechanics and Mining Science, Vol. 7, pp. 561-575.

Wawersik, W.R. and Brace, W.F. (1971) Post-failure behavior of a granite and diabase, Rock Mechanics, Vol. 3, pp. 61-85.

Wong, T.F., Szeto, H. and Zhang, J. (1992) Effect of loading path and porosity on the failure mode of porous rocks, Applied Mechanics Review, Vol. 45, pp. 281-293.

Wyss, M. and Brune, J. (1967) The Alaska earthquake of 28 March 1964: A complex multiple rupture, Bulletin of the Seismological Society of America, Vol. 57, pp. 1017-1023.

Zhang, J., Wong, T.F. and Davis, D.M. (1990) High pressure embrittlement and shear-enhanced compaction of Berea sandstone: acoustic emission measurement and microstructural observation, in Proceedings of the 31st U.S. Symposium on Rock Mechanics: Rock mechanics contributions and challenges (RaSiM6), W.A. Hustrulid and G.A. Johnson (eds), A.A. Balkema, Rotterdam, pp. 653-660. 
